\title{
The Vacuum System for the PEP II High Energy Ring Straight Sections
}

\author{
U. Wienands, E. Daly, S. A. Heifets, A. Kulikov, N. Kurita, M. Nordby, \\ C. Perkins, E. Reuter, J. T. Seeman, F. C. Belser, J. Berg, \\ F. R. Holdener, J.A. Kerns, M. R. McDaniel, W. Stoeffl
}

This paper was prepared for submittal to the European Particle Accelerator Conference

Stiges, Spain

May 1-5, 1995

May 1, 1995

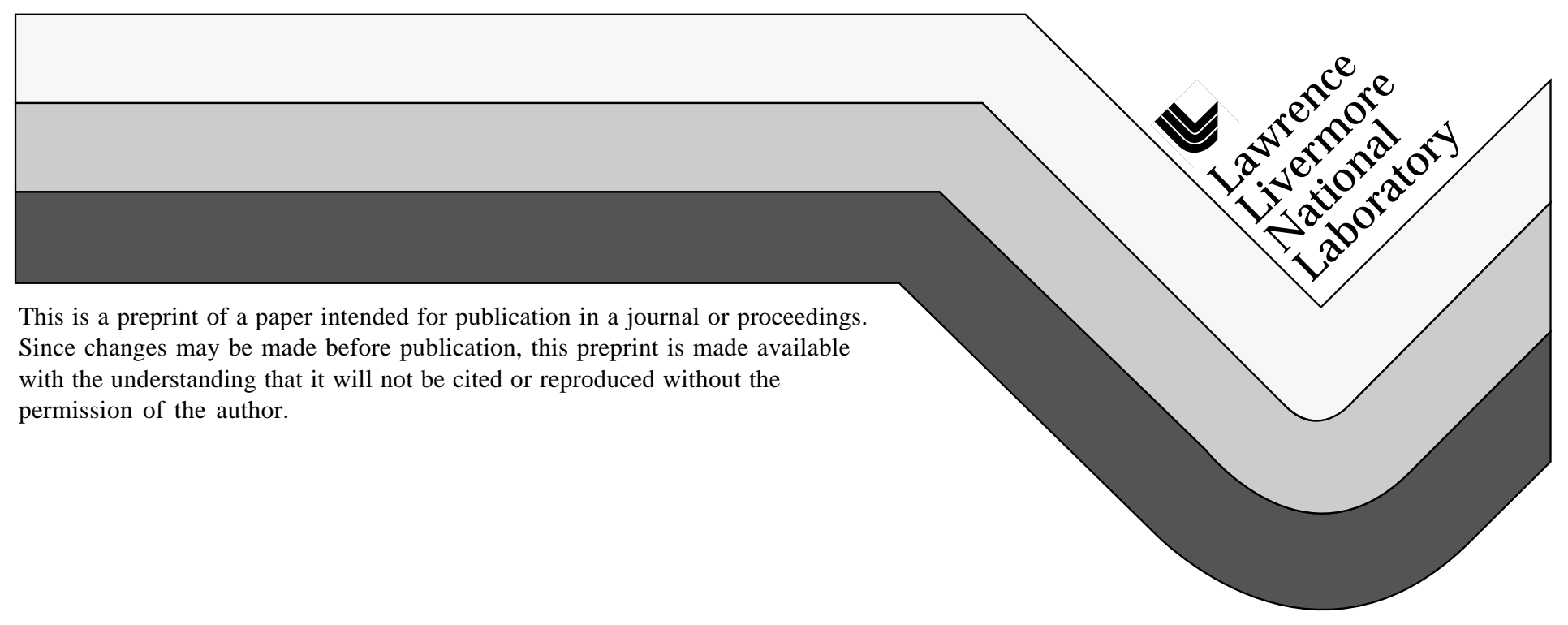




\section{DISCLAIMER}

This document was prepared as an account of work sponsored by an agency of the United States Government. Neither the United States Government nor the University of California nor any of their employees, makes any warranty, express or implied, or assumes any legal liability or responsibility for the accuracy, completeness, or usefulness of any information, apparatus, product, or process disclosed, or represents that its use would not infringe privately owned rights. Reference herein to any specific commercial product, process, or service by trade name, trademark, manufacturer, or otherwise, does not necessarily constitute or imply its endorsement, recommendation, or favoring by the United States Government or the University of California. The views and opinions of authors expressed herein do not necessarily state or reflect those of the United States Government or the University of California, and shall not be used for advertising or product endorsement purposes. 


\title{
THE VACUUM SYSTEM FOR THE PEP II HIGH ENERGY RING STRAIGHT SECTIONS. *
}

\author{
U. Wienands, E. Daly, S.A. Heifets, A. Kulikov, N. Kurita, M. Nordby, C. Perkins E. Reuter, \\ J.T. Seeman, SLAC, Stanford, CA; and
}

F.C. Belser, J. Berg, F.R. Holdener, J.A. Kerns, M.R. McDaniel, W. Stoeff, LLNL, Livermore, CA

\begin{abstract}
The six straight insertions of the PEP II High Energy Ring (HER)[1] serve various functions: lattice tuning, beam injection and abort, providing space for rf cavities, longitudinal and transverse feedback, beam diagnostics and the interaction point. A stainless steel vacuum system has been designed; prototypes are currently being built. Cooling is required due to radiation coming from the last arc dipole and resistive losses in the vacuum chamber. Although the nominal beam current of the HER is $1 \mathrm{~A}$ the vacuum system is designed for $3 \mathrm{~A}$ to provide margin and an upgrade path.
\end{abstract}

\section{DESIGN REQUIREMENTS}

The PEP II Conceptual Design Report (CDR, Ref.[2]) calls for an average pressure in the straights of 3 nTorr, mainly determined by beam lifetime considerations. In order to achieve this pressure, about $3 \mathrm{~m}$ pump spacing would be required in the first $6-7$ cells of each straight section due to the still significant synchrotron radiation at $3 \mathrm{~A}$ current. Initially, lower intensities are expected and, therefore, for first commissioning $220 \mathrm{l} / \mathrm{s}$ ion getter pumps will be provided at every quadrupole only ( $\approx 7 \mathrm{~m}$ pump spacing). Fig. 1 shows the pressure profile and gas load at $1 \mathrm{~A}$ beam

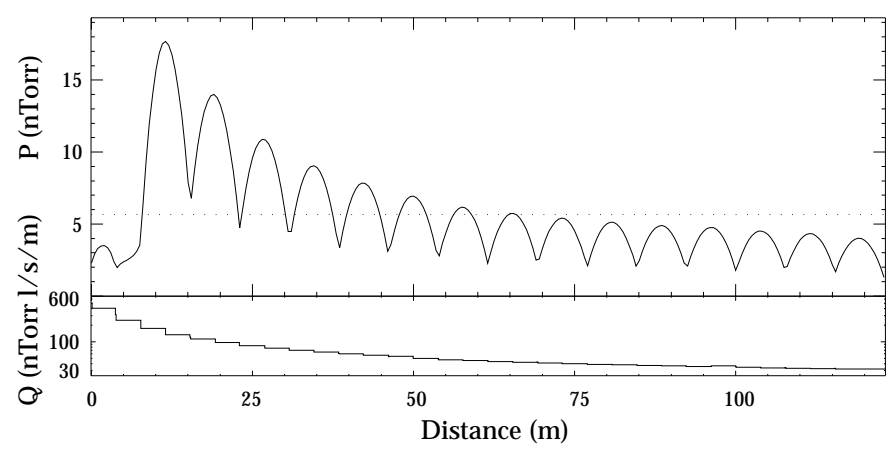

Figure. 1. Pressure and gas load along an HER straight section

current. For this calculation, a photon-induced desorption rate of $\eta=2 \times 10^{-6}$ is assumed. To achieve this value, the vacuum components will be glow-discharge cleaned after chemical cleaning. Initially, $\eta$ will be higher but the cleaning effect of synchrotron radiation will reduce $\eta$, especially so at the upstream end of the straight. Over time, $\eta$ is expected to go down and eventually be less than $10^{-6}$. If it is

\footnotetext{
*Work supported by US Department of Energy under contract DEAC03-76SF00515, DE-AC03-76SF00098, DE-AC03-81ER40050, DEAS03-76ER70285 and W-7405-Eng-48
}

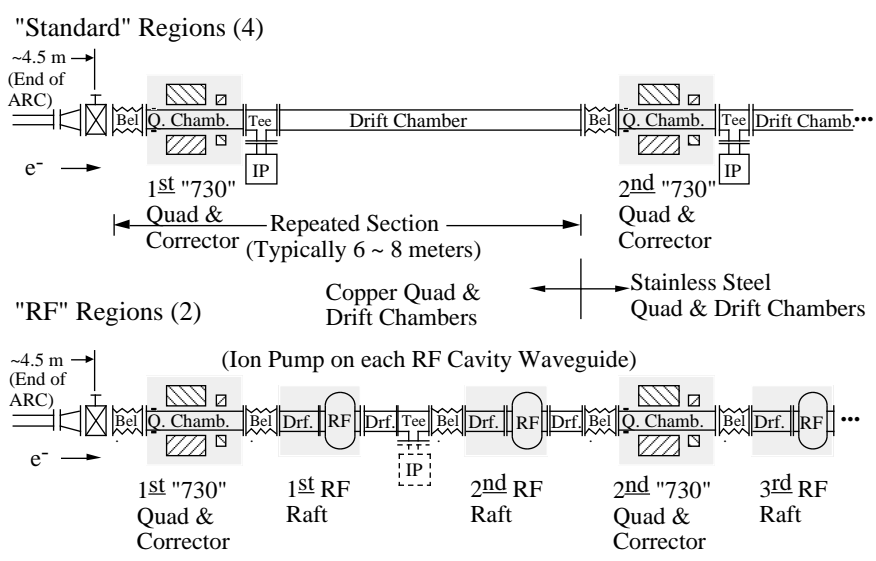

Figure. 2. Layout of arc-straight transitions

found that the pressure does not reach the required level, additional pumping tees and pumps will be installed in the first cells. The vacuum system of each straight section can be separated from the adjacent arcs by gate valves located right after the transition in shape from the octogonal profile used in the arcs to circular pipe. The transition regions are shown in Fig. 2.

The expected distribution of the power deposition along the beam pipe for $3 \mathrm{~A}$ beam current is shown in Fig. 3 At the upstream end of each straight section it is dominated by the synchrotron radiation; this causes the pressure rise in Fig. 1. Additional power is being deposited by direct $I^{2} R$ losses due to image currents and by losses arising from higher-order modes (HOM) traveling along the vacuum system, which will dissipate predominantly in the stainless steel walls. Cu extrusions will be used rather than

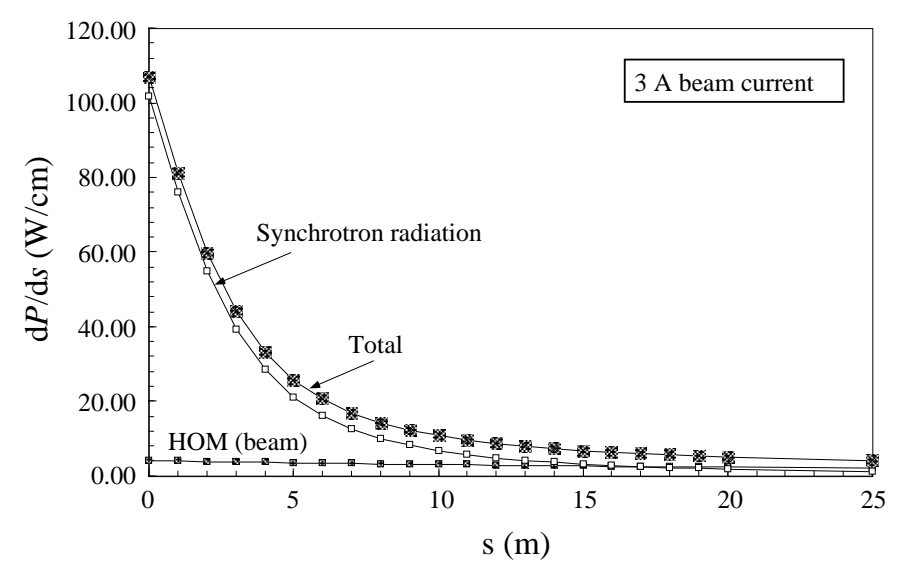

Figure. 3. Power deposition along beam pipe 


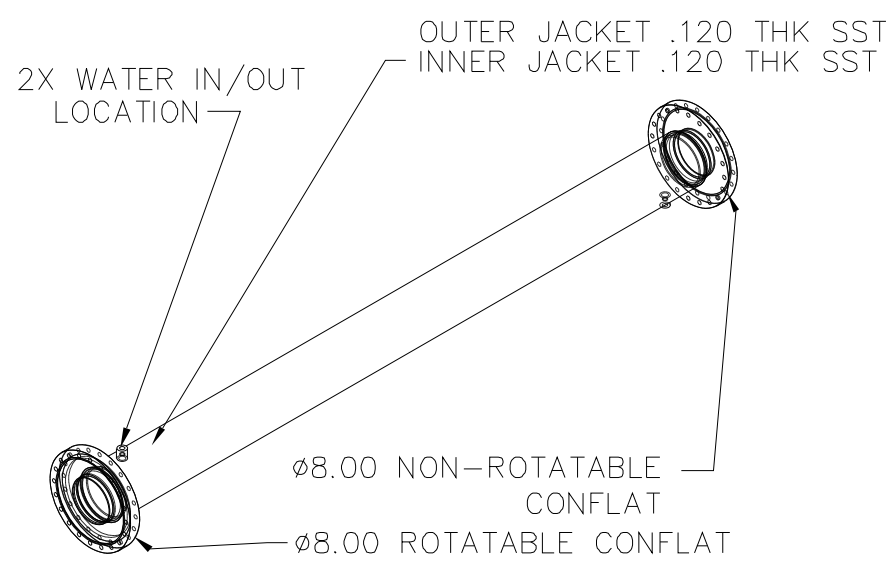

Figure. 4. Drift chamber

stainless steel in the first $4.2 \mathrm{~m}$ using the same shape as in the dipoles of the arcs.[3], [4] The pump chamber provides a convenient, shielded area for four pump ports to hold NEG cartridges.

The heating of an uncooled beam pipe as a function of power can be calculated approximately. We have performed a test heating a $1 \mathrm{~m}$ long sample of ss pipe by direct current and measuring its temperature. Experiment and calculation are consistent and show that a linear power density of $1 \mathrm{~W} / \mathrm{cm}$ along the pipe will lead to temperatures of about $70-80^{\circ} \mathrm{C}$ if not cooled; this would lead to undesirable outgassing.

Due to the high currents and short bunches, a strict impedance budget is enforced for the whole HER vacuum system. The total inductive impedance is limited by the bunch lengthening threshold to less than $200 \mathrm{nH}$ for the whole ring. Narrow band impedance limits are frequency dependent; but the contribution of the vacuum system should be insignificant compared to that of the rf cavities. The existence of any gaps along the inner wall (e.g. at flanges) is being avoided. Care is being taken to avoid any possibility of mode trapping between adjacent shape transitions in the beam pipe. Almost every discontinuity is being tapered to less than $10^{\circ}$ angle. An impedance committee has been set up to scrutinize every significant discontinuity and transition in the vacuum system.[5]

\section{COMPONENT DESIGN}

The straight section vacuum system is modular, with four basic components as shown in Fig. 2: Drift chamber, Quadrupole chamber, Pumping Tee and Bellows module. AISI 304L stainless steel is used throughout. The beam pipe is required to be seamless to avoid the possibility of seam-related problems. In addition, no welds at all are permitted to be within any of the magnetic elements as improperly carried out welds could change the $\mu$ of the material away from unity. The $\mu$ of the material has been specified to be less than $\mu_{r}=1.05$ and will be inspected upon receiving of the pipe stock.

\section{A. Drift Chamber}

The drift chamber is designed using two concentric round ss pipes with a $1 / 16$ in. gap for the cooling water. A sketch of the chamber is shown in Fig. 4. The concentric chamber design allows for fairly uniform cooling around the azimuth of and along the whole chamber; a wire coil inserted between chamber and cooling jacket together with some extra spacers at the ends assists to this end. Conflat flanges are welded on at each end.

\section{B. Quadrupole Chamber}

The cooling-jacket concept used for the drift chamber can not be used for the quadrupole chamber. The $50 \mathrm{~mm}$ pole radius of the quadrupole magnets and the inner radius requirement of $44.5 \mathrm{~mm}$ or larger proved to be mutually exclusive unless expensive custom-made pipe stock be purchased. Therefore a different concept is being pursued using regular $44.5 \mathrm{~mm}$ inner radius "Schedule 10" piping (Fig. 5). The pipe is coated with a $1 \mathrm{~mm}$ copper layer and four $6.35 \mathrm{~mm} \mathrm{Cu}$ cooling pipes will be soldered to the outside. The copper layer increases the heat conductance both from areas of the pipe not directly under the cooling channels. At each flange the cooling pipe will be wrapped around the beam pipe for increased cooling. In this way, margin is provided against vertical displacement of the synchrotron radiation fan and areas under the flanges receive adequate cooling as well.

\section{Pumping Tee}

The pumping tee module is shown in Fig. 6. The pump is attached to the 8 in flange welded to a plenum. A slotted $\mathrm{Cu}$ insert provides the rf shield necessary to reduce the impedance of the pumping tee. 8 in flanges are used rather than 6 in to avoid the need for blind-tapped holes. The conductance of the whole assembly is calculated to be about $470 \mathrm{l} / \mathrm{s}$; this results in an effective pumping speed of $150 \mathrm{l} / \mathrm{s}$ for a $220 \mathrm{l} / \mathrm{s}$ pump. Those tees located near the upstream end of the straight sections have to be able to handle significant synchrotron radiation. In order to be able to do so, $1 \mathrm{~cm}$ wide strips at the side of the Tee are not slotted and a stainless cooling line is brazed to the insert.

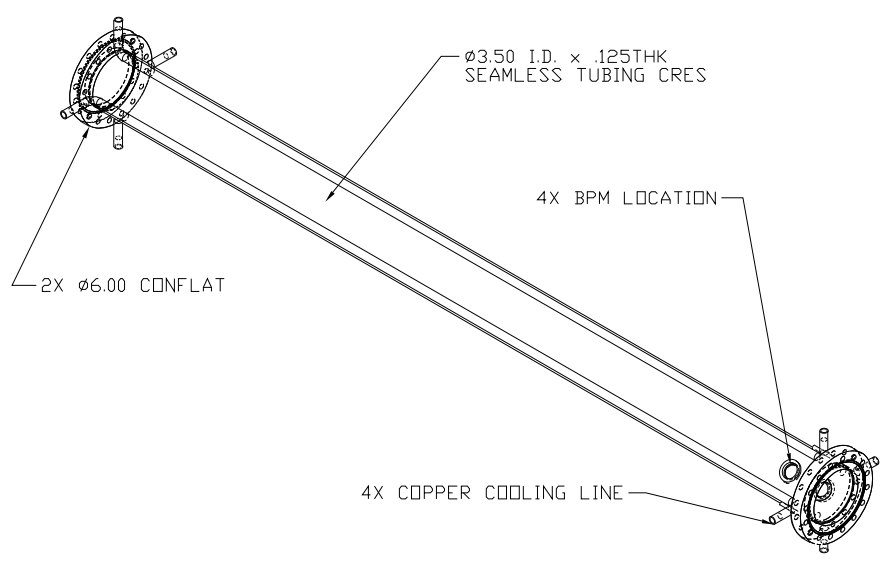

Figure. 5. Quadrupole chamber 
The long slots are transparent to TE field modes emanating from the rf cavities and also generated by mode conversion of the TM fields associated with the beam. These can cause heating in the pumps and will therefore be screened by a thin $\mathrm{Cu}$ sheet with $5 \mathrm{~mm}$ wide slots orthogonal to the slots on the insert. The long slots also increase the effective diameter of the beam pipe and, thus, potentially can lead to trapped modes. To avoid this possibility the aperture will be slightly restricted in the region of the slots, by about $0.5 \mathrm{~mm}$. MAFIA calculations confirm the effectiveness of this approach.

\section{Bellows Module}

The bellows module is the most challenging part of the vacuum system. The bellows themselves have to be protected from too much power dissipation and would present an unacceptable impedance to the beam; therefore, they will be shielded. The shield has to present as smooth a surface as possible to the beam to reduce the inductive broad-band impedance and has to do this over the full operational extension/contraction range of about $5 \mathrm{~mm}$. In addition, it has to sustain a contraction of up to $19 \mathrm{~mm}$ without damage if in situ bake-out were to take place.

The shield uses a sliding-finder design with the fingers of the rf shield riding outside on the rim of a slightly conical stainless stub. Figure 7 shows a sketch of the bellows assembly. The fingers are straight where exposed to the beam to avoid creating a bulge in the crossectional area that could act as a cavity. The total broad band impedance of all $\approx 100$ straight-section bellows modules is about $4.5 \mathrm{nH}$ which is acceptable. The fingers are made of dispersionstrengthened copper (GlidCop) rather than $\mathrm{BeCu}$, for improved strength and thermal handling and will be silver coated. The stub, made of stainless, will be copper coated on the inside to reduce $I^{2} R$ and HOM losses and will have a Rhodium coating at the contact area. A taper at the up-

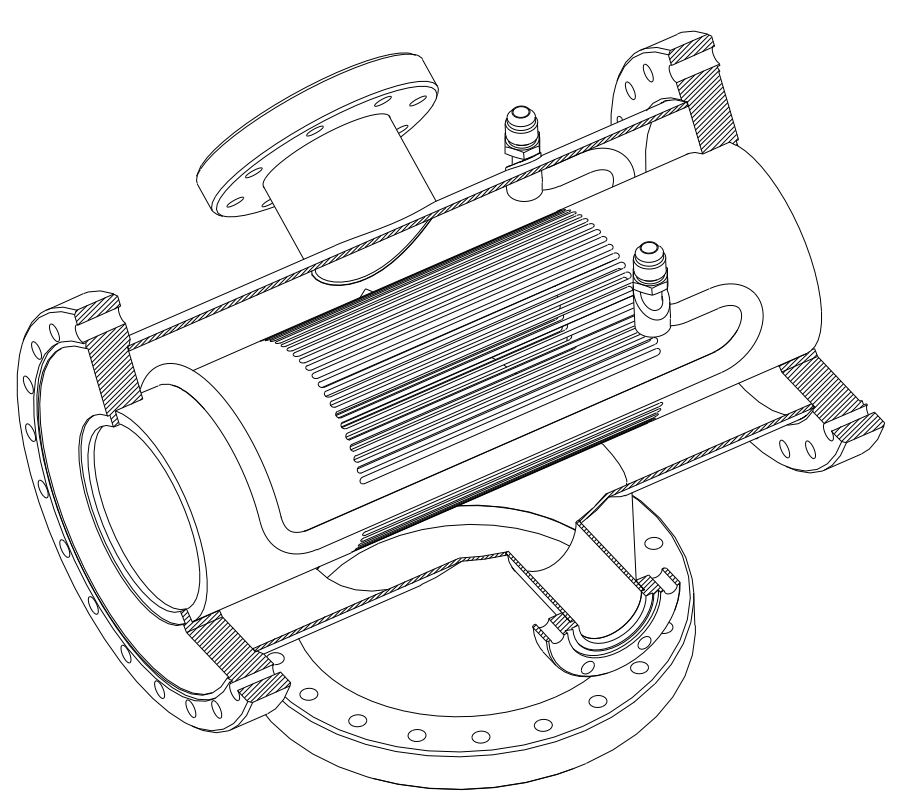

Figure. 6. Pumping Tee

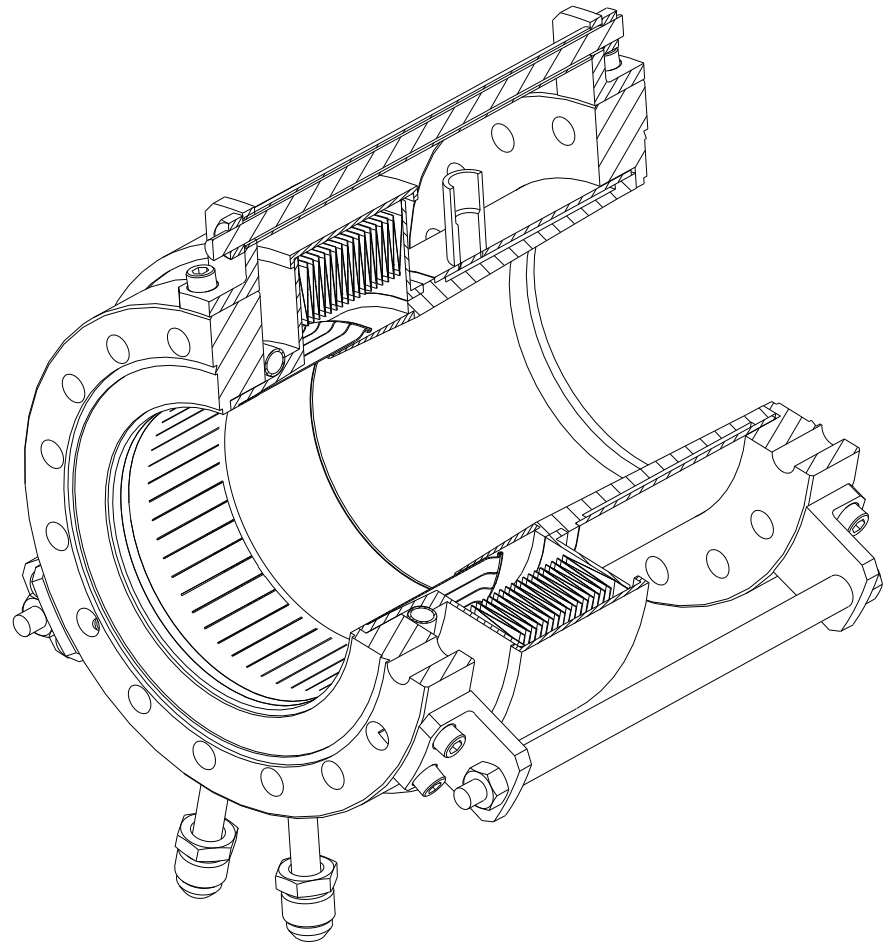

Figure. 7. Bellows assembly

stream end of the bellows protects the fingers and the stub from synchrotron radiation.

A test fixture has been built to test the stability of the fingers over at least 200000 compression-expansion cycles at operating temperatures. Contact resistance and dust production can be assessed in this way. A current of $2 \mathrm{~A}$ per finger can be injected into the fixture, but the frequency of $2 \mathrm{MHz}$ is too low to fully test the current carrying ability of the fingers.

\section{References}

[1] U. Wienands et al., "Status of the High Energy Ring of the PEP II B-Factory", these proceedings.

[2] M. Zisman, Ed., "PEP-II An Asymmetric B Factory", Conceptual Design Report, SLAC-416.

[3] C. Perkins et al., "Vacuum System of the PEP-II High Energy Ring", Proc. EPAC, London, UK, 1994.

[4] E.F. Daly et al., "Stretch Forming Vacuum Chambers for the PEP-II B-Factory High Energy Ring", these proceedings.

[5] S.A. Heifets et al., "Impedance Budget of the PEP II B-Factory", these proceedings. 


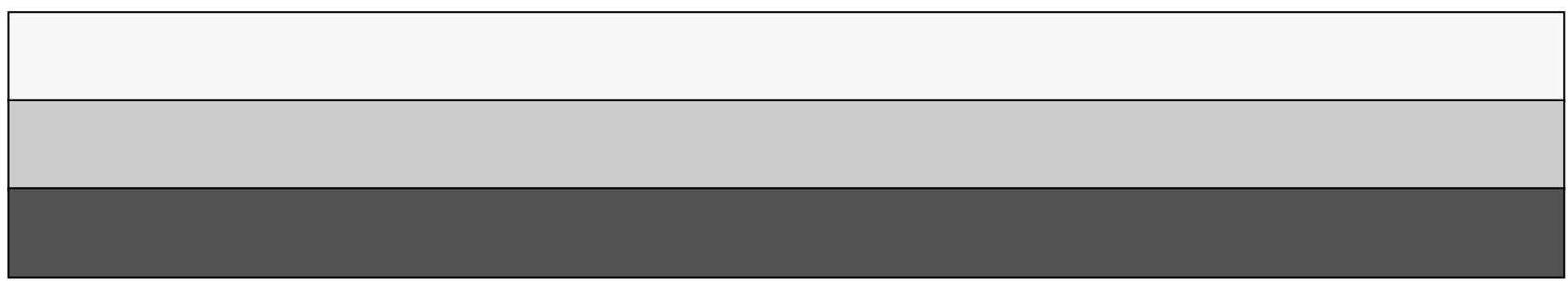

